\title{
Circular Economy in the Manufacture of Bioplastics: From Sewage Sludge to Plastic Bottle ${ }^{\dagger}$
}

\author{
N. Anes García 1,* , F. Blanco Álvarez ${ }^{2}$ and A. L. Marqués Sierra ${ }^{2}$ \\ 1 ELMAC-Ingenieria, Dirección, 33203 Gijón, Spain \\ 2 School of Mining, Energy and Materials Engineering, University of Oviedo, Independencia, 13, \\ 33003 Oviedo, Spain; franblanco@uniovi.es (F.B.Á); marquesantonio@uniovi.es (A.L.M.S.) \\ * Correspondence: noeanes@gmail.com \\ + Presented at the 2nd International Research Conference on Sustainable Energy, Engineering, Materials and \\ Environment (IRCSEEME), Mieres, Spain, 25-27 July 2018.
}

Published: 26 November 2018

\begin{abstract}
The main objective of this study is the potential evaluation of obtaining bioplastics through biodegradable polyesters synthesized by bacteria, present in the anaerobic treatment of urban and industrial wastewater, which have a series of characteristics to consider as their processing as material bioplastic In Asturias, more than 70,000 tons of sludge are produced and, by applying circular economy criteria and technologies for the production of bioplastics from wastewater, a synergy could be obtained that would allow the reuse of sludge by valorization as raw material. to produce bioplastics. This valorization can be carried out mainly through the combination of two technologies, on the one hand, anaerobic fermentation to produce volatile fatty acids and on the other the generation of bacterial populations that produce Polyhydroxyalkanoates (PHA's). The PHAs are obtained from the microorganisms present in the sludge generated in the wastewater treatment process.
\end{abstract}

Keywords: bioplastics; PHA; sludge; VFA; water treatment plant

\section{Introduction}

Biopolymers can be classified according to their source, from which the most important biopolymers on the market divided into three subgroups will be analyzed: polymers based on renewable resources (starch and cellulose), biodegradable polymers based on bio-derived monomers (vegetable oils and lactic acid) and biopolymers synthesized by microorganisms (polyhydroxyalkanoates (PHA)).

Among the great variety of these biodegradable plastics, a family of more than 40 poly-hydroxy alkanoates (PHAs) and their copolymeric derivatives has emerged as an attractive alternative, due to its complete biodegradability. PHAs are linear aliphatic polyesters composed of fatty acid monomers and polylactic acid. The presence of PHA in activated sludge has been demonstrated as an intermediate metabolic product in wastewater treatment. Activated sludge is the biological material produced in wastewater treatment. This treatment consists of combining wastewater with microorganisms to reduce the organic load of the waters. This combination is called mixed liquor.

Once the water has been treated sufficiently, the excess liquor is discharged into sedimentation tanks. After a period in these tanks, the supernatant of the mud can be separated. The supernatant continues to be treated before it is discharged, while part of the sludge is used to reseed the new untreated water and another part represents the excess of activated sludge. The excess sludge is extracted from the system to maintain the biomass-substrate balance ratio. 
We consider it relevant to analyze the possibility of producing PHB in Asturias using the excess of activated sludge from an effluent treatment plant and the derived wastewater as renewable and economic sources of biomass and carbon, respectively. This would have two great advantages: on the one hand, a reduction in the cost of production of $\mathrm{PHB}$, and on the other, a decrease in the volume of the discarded activated sludge, because of the PHB extraction.

Due to the environmental pollution generated by both urban and industrial wastewater, the revaluation of this type of wastewater represents a technological system and an environmental alternative that we achieve an innovative and efficient way of bioplastic materials.

The regulatory requirements for discharges, as well as the need to reuse water in the industry, make this project be considered as a new, innovative alternative that eliminates water pollution while enabling the reincorporation of wastewater into the process. productive.

The rapid and marked progress that has been made in recent years in the science and technology of polymers has created new plastic materials with excellent physical properties and durability. However, plastic products usually have applications for single use, especially in food packaging and medical applications. Since these materials are not biodegradable they can remain on the surface of the earth for hundreds of years without considerable changes in their structure.

The fact that the vast majority of plastic materials produced around the world are nondegradable, implies that their waste process represents a great problem for society and for the environment. This is a problem that grows exponentially every day, estimating in 25 million tons per year the rate of accumulation of this waste in the environment

The consumption of these non-degradable plastics represents a very large negative impact on the environment. Besides the time for its decomposition, the fauna around the spills, of this type of materials, can be affected in diverse ways, affecting its habitat or feeding. Even being able to cause the death of certain specimens.

PHAs are natural aliphatic polyesters that are synthesized and stored in the cytoplasm of the cells of prokaryotic organisms, such as bacteria and cyanobacteria, as carbon stores and energy in the form of insoluble granules.

\section{Conclusions}

Generation of a biodegradable plastic of high social interest, which can respond to the growing concern of society for the negative environmental burden that both wastewater and plastics production have. The evaluation of the effectiveness of the valorization system proposed on the final quality of the effluent, the productive performance and the amount of by-products generated and products used, gives interesting results in the recovery of useful materials from the waste, obtaining high value products added (both economic and environmental). Obtaining a limited positive impact on employment with the creation of new jobs in the water treatment sector. Allowing a circular economy in the manufacture of plastics, as we would use a waste as raw material to obtain plastics that are easily recycled and degraded. Closure of the water cycle as a resource. recycling and subsequent application. Improvement of the water footprint due to a better use of this vital resource, limited and scarce.

\section{References}

1. Volova, T.; Gladysshev, I.; Trusova, Y.; Zhila, N. Degradation of polyhydroxyalkanoates in eutrophic reservoir. Polym. Degrad. Stab. 2007, 92, 580-586.

2. De Almeida, A.; Ruiz, J.A.; López, N.I; Pettinari, M.J. Bioplasticos: Una alternativa ecológica. Rev. Quím. Viva 2004, 3, 122-133.

3. Aldor, I.S.; Keasling, J.D. Process design for microbial plastic factories: Metabolic engineering of polyhydroxyalkanoates. Curr. Opin. Biotechnol. 2003, 14, 475-483.

4. Valappil, P.; Boccaccini, R.; Bucke, C.; Roy, I. Polyhydroxyalkanoates in Gram positive bacteria: Insights from the genera Bacillus and Streptomyces. Anton. Leeuwenhoek 2007, 91, 1917.

5. Wu, Q.; Huang, H.; Hu, G.; Chen, J.; Ho, K.; Chen, G. Production of poly-3-hydroxybutyrate by Bacillus sp. JMa5 cultivated in molasses media. Anton. Leeuwenhoek 2001, 80, 111-118. 
6. Borah, B.; Thakur, P.; Nigam, J. The influence of nutritional and environmental conditions on the accumulation of poly- $\beta$-hydroxybutyrate in Bacillus mycoides RLJ B-017. J. Appl. Microbiol. 2002, 92, 776783.

7. Katırcıoğlu, H.; Aslım, B.; Yüksekdað, Z.N.; Mercan, N.; Beyatlı, Y. Production of poly- $\beta$-hydroxybutyrate (PHB) and differentiation of putative Bacillus mutant strains by SDS-PAGE of total cell protein. Afr. J. Biotechnol. 2003, 2, 147-149.

8. Yilmaz, M.; Soran, H.; Beyatli, Y. Determination of poly- $\beta$-hydroxybutyrate (PHB) production by some Bacillus sp. World J. Microbiol. Biotechnol. 2005, 21, 565-566.

(C) 2018 by the authors. Licensee MDPI, Basel, Switzerland. This article is an open access article distributed under the terms and conditions of the Creative Commons Attribution (CC BY) license (http://creativecommons.org/licenses/by/4.0/). 